\title{
Distinct molecular features of colorectal carcinoma with signet ring cell component and colorectal carcinoma with mucinous component
}

\author{
Shuji Ogino ${ }^{1,2,3}$, Mohan Brahmandam², Mami Cantor ${ }^{2}$, Chungdak Namgyal², \\ Takako Kawasaki ${ }^{2}$, Gregory Kirkner ${ }^{4}$, Jeffrey A Meyerhardt',3,4, Massimo Loda ${ }^{1,2,3}$ \\ and Charles S Fuchs ${ }^{2,3,4}$ \\ ${ }^{1}$ Department of Pathology, Brigham and Women's Hospital, Boston, MA, USA; ${ }^{2}$ Department of Medical \\ Oncology, Dana-Farber Cancer Institute, Boston, MA, USA; ${ }^{3}$ Harvard Medical School, Boston, MA, USA and \\ ${ }^{4}$ Department of Medicine, Brigham and Women's Hospital, Boston, MA, USA
}

\begin{abstract}
Signet ring cell carcinoma and mucinous carcinoma are distinct subtypes of colorectal adenocarcinoma. The morphologic and molecular spectra of colorectal carcinomas with various signet ring cell components and colorectal carcinomas with various mucinous components, compared to non-mucinous adenocarcinomas, have not been examined. The study groups consisted of 39 carcinomas with various signet ring cell components ('the signet group'), 167 carcinomas with various mucinous components ('the mucinous group'), and 457 nonmucinous adenocarcinoma. We visually estimated the amounts of signet ring cell and mucinous components in tumors, and subclassified the signet and mucinous groups according to the amount of each component $(\leq 19,20-49$, and $\geq 50 \%)$. We sequenced $B R A F$ and $K R A S$, analyzed for microsatellite instability (MSI) and 18q loss of heterozygosity (LOH), and performed immunohistochemistry for TP53, cyclooxygenase-2 (COX2), MLH1, 0-6-methylguanine DNA methyltransferase (MGMT), p16 (CDKN2A), and fatty acid synthase (FASN). Signet ring cell carcinoma ( $\geq 50 \%$ signet ring cell tumors) and $\leq \mathbf{4 9} \%$ signet ring cell tumors showed similar molecular features. Except for MSI and MGMT, $\geq \mathbf{5 0} \%$ mucinous tumors and $\leq \mathbf{4 9} \%$ mucinous tumors also showed similar molecular features. BRAF mutations, MSI, and MLH1 loss were more frequent in both the signet and mucinous groups than nonmucinous carcinoma. More frequent KRAS mutations and less frequent p16 loss and TP53 positivity were observed in the mucinous group than nonmucinous carcinoma. 18q LOH and COX2 overexpression were less common in the signet group than nonmucinous carcinoma. FASN levels were highest in the mucinous group, followed by nonmucinous carcinoma, and lowest in the signet group. In conclusion, a minor $(\leq 49 \%)$ signet ring cell or mucinous component in colorectal carcinoma suggests molecular features similar to $\geq \mathbf{5 0} \%$ signet ring cell or mucinous carcinoma, respectively. Signet ring cell carcinoma and mucinous carcinoma are related subtypes of colorectal adenocarcinoma, but have molecular features distinct from each other.
\end{abstract}

Modern Pathology (2006) 19, 59-68. doi:10.1038/modpathol.3800482; published online 12 August 2005

Keywords: BRAF; colon cancer; COX2; fatty acid synthase; MSI; mucinous; signet ring cell

Signet ring cell colorectal carcinoma and mucinous colorectal carcinoma are subtypes of colorectal adenocarcinoma with prominent mucin secretion. A unique pathologic feature of signet ring cell carcinoma is the presence of signet ring cells, which

Correspondence: Dr S Ogino, MD, PhD, Department of Pathology, Brigham and Women's Hospital, 75 Francis Street, Boston, MA 02115, USA.

E-mail: shuji_ogino@dfci.harvard.edu

Received 3 June 2005; revised 8 July 2005; accepted 10 July 2005; published online 12 August 2005 are single tumor cells with intracytoplasmic mucin displacing their nuclei aside. In contrast, mucinous colorectal carcinoma is characterized by abundant extracellular mucin produced by tumor cells. By definition, a $50 \%$ or greater signet ring cell component is required for the designation of signet ring cell colorectal carcinoma. Mucinous colorectal carcinoma has also $50 \%$ or more mucinous components. Signet ring cell colorectal carcinoma has been associated with poor clinical outcomes. ${ }^{1-6}$ A number of studies have examined the molecular features of signet ring cell colorectal carcinoma and mucinous 
colorectal carcinoma. ${ }^{3-5,7}$ However, the molecular markers these studies examined were few. Furthermore, the biological significance of a minor signet ring cell or mucinous component $(\leq 49 \%$ of the tumor) in otherwise conventional colorectal adenocarcinoma has not been studied. In the current practice of surgical pathology, there is no definitive rule on how to report a minor component of signet ring cells or mucinous features in colorectal adenocarcinoma. We hypothesized that carcinomas with a $\leq 49 \%$ signet ring cell or mucinous component might have molecular features similar, if not identical, to colorectal carcinoma, with a $\geq 50 \%$ signet ring cell or mucinous component, respectively.

A number of genes and pathways have been implicated in colorectal carcinogenesis, and in some cases these genes show differential rates of alteration among different morphologic types of carcinoma. RAS and RAF proteins participate in the RAS-RAFMEK-ERK-MAP kinase pathway, which mediates cellular responses to growth signals. ${ }^{8}$ Somatic mutations of KRAS are common in various human cancers including colorectal carcinoma. Activating mutation of the BRAF gene is common in malignant melanoma, but less frequent in colorectal carcinoma. ${ }^{9} B R A F$ mutations in colorectal carcinoma were reported to occur more commonly in those cases with high degree of microsatellite instability (MSI-H), ${ }^{10}$ but less frequently in colorectal carcinoma in patients with germline mutation in one of mismatch repair genes than in sporadic MSI-H tumors. ${ }^{11}$ Mutations of $B R A F$ are associated with MLH1 promoter methylation in sporadic colorectal carcinoma, ${ }^{12}$ and mucinous colorectal carcinoma. ${ }^{4}$ Both signet ring cell colorectal carcinoma and mucinous colorectal carcinoma are associated with MSI-H. ${ }^{3-5}$ In addition, frequent $B R A F$ mutation and infrequent KRAS mutation have been reported in mucinous colorectal carcinoma, compared to nonmucinous adenocarcinoma. ${ }^{4}$

Cyclooxygenase-2 (COX2) has been shown to be overexpressed in colorectal cancer, ${ }^{13}$ and a high level of COX2 expression is associated with poor prognosis. ${ }^{14}$ Recently, COX2 has been shown to be a target of mutant KRAS. ${ }^{15}$ The new COX2-specific inhibitor celecoxib has been shown to inhibit the growth of colorectal cancer cells. ${ }^{16}$

Fatty acid synthase (FASN) is involved in de novo lipogenesis, catalyzing the reaction steps in the conversion of acetyl-CoA and malonyl-CoA to longchain saturated fatty acid. ${ }^{17}$ FASN overexpression is commonly observed in human cancers, ${ }^{18-22}$ including colorectal cancer. ${ }^{23-25}$ FASN overexpression has been associated with poor prognosis in breast, ovarian, and prostate cancers, and soft tissue sarcomas. ${ }^{18,20-22,26,27}$ FASN inhibitor C75 has antitumor activity, ${ }^{28}$ and causes apoptosis of p53deficient colon cancer cells. ${ }^{29}$ The FASN inhibitor, Orlistat, used to treat obesity, may serve as a potential anticancer drug. ${ }^{30}$ FASN overexpression may be beneficial for tumor cells to retain more energy source and survive.
In this study, we characterize the molecular features of colorectal carcinoma with signet ring cell component, and colorectal carcinoma with mucinous component, but no signet ring cell component, and compared them to those of nonmucinous nonsignet ring cell colorectal adenocarcinoma. This study is the first to comprehensively examine the morphologic and molecular spectra of signet ring cell and mucinous differentiations in colorectal carcinoma. We analyzed for a number of molecular abnormalities, including $B R A F, K R A S$, MSI, $18 \mathrm{q}$ loss of heterozygosity (LOH), and expression of p53 (TP53), COX2, p16 (CDKN2A, also known as INK4a), O-6-methylguanine DNA methyltransferase (MGMT), MLH1, and FASN. Our results indicate that a minor signet ring cell or mucinous component in colorectal carcinoma implies molecular features similar to colorectal carcinoma, with a $\geq 50 \%$ signet ring cell or mucinous component, respectively.

\section{Materials and methods}

\section{Tissue Specimens and Histopathologic Evaluations}

Tissue collection and analysis in this study have been approved by the Dana-Farber/Harvard Cancer Center Institutional Review Board. Colorectal adenocarcinoma resection specimens were collected from participants of the Nurses' Health Study and Health Professional Follow-up Study cohorts. ${ }^{31,32}$ Informed consents from all study participants have been obtained prior to this study. Tumors were randomly selected from these cohorts, based on availability of tumor tissue samples and assay results at the time of this study. Hematoxylin and eosin-stained slides of the tumors were reviewed, and the percentages of signet ring cell component and mucinous component were estimated under a light microscope. Tumors with signet ring cells (consisting 'the signet group') were classified according to the amount of their signet ring cell component: $\leq 19,20-49$, and $\geq 50 \%$. After excluding tumors with signet ring cells, tumors with any mucinous component (consisting 'the mucinous group') were classified according to the amount of their mucinous components: $\leq 19,20-49$, and $\geq 50 \%$. The colorectal adenocarcinomas without any mucinous or signet ring cell component were designated as nonmucinous nonsignet ring cell adenocarcinoma (also referred to as 'nonmucinous carcinoma'). There were totals of 39 carcinomas with any signet ring cell component (the signet group), 167 carcinomas with any mucinous component (the mucinous group), and 457 nonmucinous carcinomas.

\section{Genomic DNA Extraction, and Sequencing of KRAS and $B R A F$}

For DNA extraction, tumor tissue on glass slides was manually dissected excluding pure normal tissue to 
enrich tumor DNA. For tumors with a signet ring cell or mucinous component, we did not separate tumor DNA of the signet ring cell or mucinous areas from non-signet or nonmucinous areas. Instead, we analyzed pooled DNA from representative areas of the tumor. Normal DNA was obtained from normal colorectal tissue at resection margins. Genomic DNA was extracted using QIAmp DNA Mini Kit (Qiagen, Valencia, CA, USA). For whole genome amplification (WGA), genomic DNA was PCR-amplified using random 15-mer primers. ${ }^{33}$ Procedures of WGA has been validated as previously described. ${ }^{34}$ Methods of PCR and sequencing targeted for KRAS codons 12 and 13 , and $B R A F$ codon 600 , have been previously described. $^{35}$ All forward sequencing results were confirmed by reverse sequencing. KRAS sequencing was validated by the pyrosequencing technology as described previously. ${ }^{34}$

\section{Analyses for MSI and 18q $\mathrm{LOH}$}

The status of MSI was determined by analyzing variability in the length of the microsatellite markers from tumor DNA compared to normal DNA. In addition to the recommended MSI panel consisting of D2S123, D5S346, D17S250, BAT25, and BAT26, ${ }^{36}$ we used BAT40, D18S55, D18S56, D18S67, and D18S487 (ie, 10-marker panel). Primers were as follows: BAT40-F, 5' -agc caa gat taa ctt cct aca cca caa C-3'; BAT40-R, 5'-gta gag caa gac cac ctt gtc tc-3'; D18S55-F, $5^{\prime}$-gtg tct tca ata ttg att ctc tat tct agc ct-3'; D18S55-R, $5^{\prime}$-agc ttc tga gta atc tta tgc tgt g-3'; D18S56-F, $5^{\prime}$-gtg tct tcc tga agg acc tgc ctg aga ta-3'; D18S56-R, $5^{\prime}-$ cta tac ttt tta ttg tta ggg tgt g- $3^{\prime}$; D18S67-F, $5^{\prime}$-ctt ggg ttc cat ctt cag gaa a-3'; D18S67-R, $5^{\prime}$-gtg tct tat gag ata ggc cca aag cat C-3'; D18S487-F, $5^{\prime}$-gtg tct tgc caa att aaa aga atg tat att att gc-3'; D18S487-R, $5^{\prime}$-gat tt cct cgt gcg tgc $\mathrm{tt}-3^{\prime}$. Either forward or reverse primer for each marker was labeled with fluorescence, and PCR products were electrophoresed and analyzed by ABI 3730 (Applied Biosystems, Foster City, CA, USA). PCR and DNA fragment analysis for all of the markers except for D2S123, D5S346, and D17S250 was performed in duplicate. 'High degree of MSI' (MSI-H) was defined as having instability in $30 \%$ or more of the markers when results of seven or more markers were available.

LOH at each locus (D18S55, D18S56, D18S67, or D18S487) was defined as $40 \%$ or greater reduction of one of two allele peaks in duplicated runs in tumor DNA when compared to normal DNA. A tumor was defined as $18 \mathrm{q} \mathrm{LOH}$ positive when any informative marker showed LOH. A tumor was defined as $18 \mathrm{q}$ $\mathrm{LOH}$ negative when at least two markers were informative and no informative marker showed LOH.

Immunohistochemistry for p53 (TP53), FASN, p16 (CDKN2A), MLH1, MGMT, and COX2

Methods of immunohistochemistry for TP53, p16, MLH1, and MGMT were described previously. ${ }^{37-40}$
We have described methods of COX2 immunohistochemistry. ${ }^{35}$

For FASN immunohistochemistry, antigen retrieval was performed by incubating deparaffinized tissue sections in $10 \mathrm{mM}$ citrate buffer (BioGenex, San Ramon, CA, USA) by a microwave for $15 \mathrm{~min}$. Tissue sections were incubated with $3 \% \quad \mathrm{H}_{2} \mathrm{O}_{2}$ $(20 \mathrm{~min})$ to block endogenous peroxidase, and then incubated with 10\% normal goat serum in phosphate-buffered saline $(10 \mathrm{~min})$. Primary antibody against FASN (BD Biosciences, Mississauga, ON, Canada) (dilution 1:100) was applied for $60 \mathrm{~min}$ at room temperature. Then, Multilink secondary antibody (BioGenex) (20 min) and then streptavidin horseradish peroxidase (BioGenex) were applied (20 min). Sections were visualized by diaminobenzidine (DAB) (5 min) and methyl-green counterstain. FASN expression was interpreted as negative, weak $(1+)$, positive $(2+)$, and strongly positive $(3+)$, using normal colonic epithelial cells and adipose tissue as reference.

\section{Statistical Analysis}

Statistical analysis was performed using the SAS program (version 9.1, SAS Institute, Cary, NC, USA). $\chi^{2}$ test and Fisher's exact test (when a number of any category is less than 10) were utilized for the analysis on categorical data. In Tables 1-4, we ranked $P$-values as follows: between 0.05 and 0.025 $\left.{ }^{\mathrm{a}}\right)$, between 0.025 and $0.01\left(^{\mathrm{b}}\right)$, between 0.01 and $0.005\left(^{\mathrm{c}}\right)$, between 0.005 and $0.001\left(^{\mathrm{d}}\right)$, between 0.001 and $0.0001\left({ }^{\mathrm{e}}\right)$, and 0.0001 or less $\left({ }^{\mathrm{f}}\right)$.

\section{Results}

\section{MSI, MLH1 Loss, and 18q LOH}

MSI-H tumors were more frequent in the signet group (25\% or above) and the mucinous group (16$38 \%$ ) than in nonmucinous carcinoma (11\%) (Table 1). There was a statistically significant difference in frequencies of MSI-H between $\geq 50 \%$ mucinous tumors $(38 \%)$ and $\leq 19 \%$ mucinous tumors $(16 \%$; $P<0.01)$, and between 20-49\% mucinous tumors $(34 \%)$ and $\leq 19 \%$ mucinous tumors $(16 \%$; $P<0.025)$. Consistent with the MSI results, MLH1 loss was more common in both the signet group (29$40 \%$ ) and the mucinous group (13-30\%) than in nonmucinous carcinoma (10\%) (Table 1). 18q LOH was less common in $\leq 19 \%$ signet ring cell tumors $(30 \%)$ than in nonmucinous carcinoma $(64 \%)$ $(P<0.005)$ (Table 1$)$.

\section{$B R A F$ and KRAS Mutations, and TP53 Immunohistochemistry}

The most common BRAF mutation is the p.Val600Glu mutation (V600E, previously called 'V599E' mutation). All other mutations comprised only appro- 
Table 1 MSI, MLH1 loss, and 18q LOH in colorectal carcinoma with signet ring cell and mucinous components and nonmucinous adenocarcinoma

\begin{tabular}{|c|c|c|c|}
\hline Type of colorectal carcinoma & $M S I-H(\%)$ & MLH1 loss (\%) & $18 q \mathrm{LOH}$ present (\%) \\
\hline \multicolumn{4}{|c|}{ Carcinoma with signet ring cell component (the signet group) } \\
\hline$\leq 19 \%$ & $7 / 25(28 \%)^{\mathrm{b} 1}$ & $7 / 25(28 \%)^{\mathrm{b} 3}$ & $6 / 20(30 \%)^{\mathrm{d} 6}$ \\
\hline $20-49 \%$ & $2 / 3(67 \%)^{\mathrm{a} 1}$ & $2 / 5(40 \%)$ & $1 / 2(50 \%)$ \\
\hline$\leq 49 \%$ & $9 / 28(32 \%)^{\mathrm{d} 1}$ & $9 / 30(30 \%)^{\mathrm{d} 4}$ & $7 / 22(32 \%)^{\mathrm{b} 5}$ \\
\hline$\geq 50 \%$ & $2 / 8(25 \%)$ & $2 / 7(29 \%)$ & $4 / 7(57 \%)$ \\
\hline Any & $11 / 36(31 \%)^{\mathrm{d} 2}$ & $11 / 37(30 \%)^{\mathrm{d} 5}$ & $11 / 29(38 \%)^{\mathrm{b} 6}$ \\
\hline \multicolumn{4}{|c|}{ Carcinoma with mucinous component (the mucinous group) } \\
\hline$\leq 19 \%$ & $11 / 70(16 \%)^{\mathrm{b} 2, \mathrm{c}}$ & $8 / 61(13 \%)$ & $30 / 54(56 \%)$ \\
\hline $20-49 \%$ & $15 / 44(34 \%)^{\mathrm{b} 2, \mathrm{f1}}$ & $11 / 37(30 \%)^{e 1}$ & $17 / 30(57 \%)$ \\
\hline$\leq 49 \%$ & $26 / 114(23 \%)^{\mathrm{a} 2, \mathrm{~d} 3}$ & $19 / 98(19 \%)^{b 4}$ & $47 / 84(56 \%)$ \\
\hline$\geq 50 \%$ & $20 / 53(38 \%)^{\mathrm{c}, \mathrm{a} 2, \mathrm{f} 2}$ & $14 / 50(28 \%)^{\mathrm{e}^{2}}$ & $20 / 38(53 \%)$ \\
\hline Any & $46 / 167(28 \%)^{\mathrm{f} 3}$ & $33 / 148(22 \%)^{\mathrm{e} 3}$ & $67 / 122(55 \%)$ \\
\hline Nonmucinous adenocarcinoma & $38 / 351(11 \%)^{\mathrm{b} 1, \mathrm{a} 1, \mathrm{~d} 1, \mathrm{~d} 2, \mathrm{f} 1, \mathrm{~d} 3, \mathrm{f} 2, \mathrm{f} 3}$ & $36 / 352(10 \%)^{\mathrm{b} 3, \mathrm{~d} 4, \mathrm{~d} 5, \mathrm{e} 1, \mathrm{~b} 4, \mathrm{e} 2, \mathrm{e} 3}$ & $194 / 304(64 \%)^{\mathrm{d} 6, \mathrm{~b} 5, \mathrm{~b} 6}$ \\
\hline
\end{tabular}

Superscripts for statistical significance: ${ }^{\mathrm{a} 1, \mathrm{a} 2} P<0.05$; ${ }^{\mathrm{b} 1-\mathrm{b} 6} P<0.025$; ${ }^{\mathrm{c} 1} P<0.01$; ${ }^{\mathrm{d} 1-\mathrm{d} 6} P<0.005$; ${ }^{\mathrm{e} 1-\mathrm{e} 3} P<0.001$; ${ }^{\mathrm{f} 1-\mathrm{f} 3} P<0.0001$.

LOH, loss of heterozygosity; MSI-H, microsatellite instability-high.

Table 2 BRAF and KRAS mutations and TP53 immunohistochemistry in colorectal carcinoma with signet ring cell and mucinous components and nonmucinous adenocarcinoma

\begin{tabular}{|c|c|c|c|}
\hline Type of colorectal carcinoma & BRAF mutants (\%) & KRAS mutants (\%) & TP53 positive (\%) \\
\hline \multicolumn{4}{|c|}{ Carcinoma with signet ring cell component (the signet group) } \\
\hline$\leq 19 \%$ & $7 / 21(33 \%)^{\mathrm{d} 1}$ & $9 / 27(33 \%)$ & $4 / 12(33 \%)$ \\
\hline $20-49 \%$ & $0 / 2(0 \%)$ & $1 / 3(33 \%)$ & $4 / 6(67 \%)$ \\
\hline$\leq 49 \%$ & $7 / 23(30 \%)^{\mathrm{d} 2}$ & $10 / 30(33 \%)$ & $8 / 18(44 \%)$ \\
\hline$\geq 50 \%$ & $2 / 9(22 \%)$ & $0 / 8(0 \%)$ & $3 / 4(75 \%)$ \\
\hline Any & $9 / 32(28 \%)^{\mathrm{d} 3}$ & $10 / 38(26 \%)$ & $11 / 22(50 \%)$ \\
\hline \multicolumn{4}{|c|}{ Carcinoma with mucinous component (the mucinous group) } \\
\hline$\leq 19 \%$ & $9 / 61(15 \%)$ & $32 / 66(48 \%)^{\mathrm{e} 3}$ & $22 / 54(41 \%)^{\mathrm{a} 2}$ \\
\hline $20-49 \%$ & $10 / 41(24 \%)^{\mathrm{d} 4}$ & $17 / 39(44 \%)^{\mathrm{a} 1}$ & $11 / 27(41 \%)$ \\
\hline$\leq 49 \%$ & $19 / 102(19 \%)^{\mathrm{b} 1}$ & $49 / 105(47 \%)^{\mathrm{d} 5}$ & $33 / 81(41 \%)^{\mathrm{b} 2}$ \\
\hline$\geq 50 \%$ & $14 / 51(27 \%)^{e 1}$ & $15 / 49(31 \%)$ & $13 / 42(31 \%)^{\mathrm{d} 7}$ \\
\hline Any & $33 / 153(22 \%)^{e^{e 2}}$ & $64 / 154(42 \%)^{\mathrm{d} 6}$ & $46 / 123(37 \%)^{\mathrm{d} 8}$ \\
\hline Nonmucinous adenocarcinoma & $30 / 348(8.6 \%)^{\mathrm{d} 1, \mathrm{~d} 2, \mathrm{~d} 3, \mathrm{~d} 4, \mathrm{~b} 1, \mathrm{e} 1, \mathrm{e} 2}$ & $102 / 376(27 \%)^{\mathrm{e} 3, \mathrm{a} 1, \mathrm{~d} 5, \mathrm{~d} 6}$ & $181 / 322(56 \%)^{\mathrm{a} 2, \mathrm{~b} 2, \mathrm{~d} 7, \mathrm{~d} 8}$ \\
\hline
\end{tabular}

Superscripts for statistical significance: ${ }^{\mathrm{a} 1, \mathrm{a} 2} \mathrm{P}<0.05$; ${ }^{\mathrm{b} 1, \mathrm{~b} 2} \mathrm{P}<0.025$; ${ }^{\mathrm{d} 1-\mathrm{d} 8} P<0.005$; ${ }^{\mathrm{e} 1-\mathrm{e} 3} P<0.001$.

Table 3 Loss of MGMT and p16 (CDKN2A), and COX2 expression in colorectal carcinoma with signet ring cell and mucinous components and nonmucinous adenocarcinoma

\begin{tabular}{|c|c|c|c|}
\hline Type of colorectal carcinoma & MGMT loss (\%) & p16 loss (\%) & COX2 positive (\%) \\
\hline \multicolumn{4}{|c|}{ Carcinoma with signet ring cell component (the signet group) } \\
\hline$\leq 19 \%$ & $5 / 19(26 \%)$ & $4 / 16(25 \%)$ & $9 / 14(64 \%)$ \\
\hline $20-49 \%$ & $0 / 2(0 \%)$ & $1 / 1(100 \%)$ & $0 / 2(0 \%)$ \\
\hline$\leq 49 \%$ & $5 / 21(24 \%)$ & $5 / 17(29 \%)$ & 9/16 (56\%) \\
\hline$\geq 50 \%$ & $0 / 4(0 \%)$ & $1 / 4(25 \%)$ & $1 / 4(25 \%)$ \\
\hline Any & $5 / 25(20 \%)$ & $6 / 21(29 \%)$ & $10 / 20(50 \%)^{\mathrm{c}}$ \\
\hline \multicolumn{4}{|c|}{ Carcinoma with mucinous component (the mucinous group) } \\
\hline$\leq 19 \%$ & $16 / 41(39 \%)$ & $6 / 45(13 \%)^{\mathrm{a} 2, \mathrm{e} 1}$ & $35 / 44(80 \%)$ \\
\hline $20-49 \%$ & $10 / 19(53 \%)^{b}$ & $4 / 19(21 \%)$ & $13 / 20(65 \%)$ \\
\hline$\leq 49 \%$ & $26 / 60(43 \%)^{\mathrm{a} 1}$ & $10 / 64(16 \%)^{\mathrm{a} 3, \mathrm{e} 2}$ & $48 / 64(75 \%)$ \\
\hline$\geq 50 \%$ & $5 / 28(18 \%)^{\mathrm{b}, \mathrm{a} 1}$ & $11 / 31(35 \%)^{\mathrm{a} 2, \mathrm{a} 3}$ & $23 / 35(66 \%)$ \\
\hline Any & $31 / 88(35 \%)$ & $21 / 95(22 \%)^{\mathrm{e} 3}$ & $71 / 99(72 \%)$ \\
\hline Nonmucinous adenocarcinoma & $71 / 208(34 \%)$ & $101 / 240(42 \%)^{\mathrm{e} 1, \mathrm{e} 2, \mathrm{e} 3}$ & $346 / 457(76 \%)^{\mathrm{c}}$ \\
\hline
\end{tabular}

Superscripts for statistical significance: ${ }^{\mathrm{a} 1-\mathrm{a} 3} \mathrm{P}<0.05$; ${ }^{\mathrm{b}} P<0.025$; ${ }^{\mathrm{c}} P<0.01$; ${ }^{\mathrm{e} 1-\mathrm{e} 3} \mathrm{P}<0.001$. 
Table 4 FASN expression in colorectal carcinoma with signet ring cell and mucinous components and nonmucinous adenocarcinoma

\begin{tabular}{|c|c|c|c|c|c|}
\hline Type of colorectal carcinoma & $3+F A S N(\%)$ & $2+F A S N(\%)$ & $1+F A S N(\%)$ & Negative & Total cases analyzed \\
\hline \multicolumn{6}{|c|}{ Carcinoma with signet ring cell component (the signet group) } \\
\hline$\leq 19 \%$ & $1(7.1 \%)$ & $3(21 \%)^{\mathrm{a} 2}$ & $5(36 \%)$ & $5(36 \%)^{b 4}$ & 14 \\
\hline $20-49 \%$ & 0 & 0 & 0 & $2(100 \%)$ & 2 \\
\hline$\leq 49 \%$ & $1(6.3 \%)$ & $3(18 \%)^{b 1}$ & $5(31 \%)$ & $7(44 \%)^{d}$ & 16 \\
\hline$\geq 50 \%$ & 0 & 0 & $1(100 \%)$ & 0 & 1 \\
\hline Any & $1(5.9 \%)$ & $3(18 \%)^{\mathrm{c} 2}$ & $6(35 \%)$ & $7(41 \%)^{\mathrm{c} 5}$ & 17 \\
\hline \multicolumn{6}{|c|}{ Carcinoma with mucinous component (the mucinous group) } \\
\hline$\leq 19 \%$ & $8(19 \%)^{\mathrm{c} 1}$ & $25(58 \%)^{\mathrm{a} 2, \mathrm{~b} 2}$ & $7(16 \%)^{\mathrm{a} 3}$ & $3(7.0 \%)^{\mathrm{b} 4, \mathrm{~b} 5}$ & 43 \\
\hline $20-49 \%$ & 0 & $11(58 \%)$ & $5(26 \%)$ & $3(16 \%)$ & 19 \\
\hline$\leq 49 \%$ & $8(13 \%)$ & $36(58 \%)^{\mathrm{b} 1, \mathrm{c} 3}$ & $12(19 \%)$ & $6(10 \%)^{\mathrm{d}, \mathrm{b} 6}$ & 62 \\
\hline$\geq 50 \%$ & $4(12 \%)$ & $16(50 \%)$ & $6(19 \%)$ & $6(19 \%)$ & 32 \\
\hline Any & $12(13 \%)^{\mathrm{a} 1}$ & $52(55 \%)^{\mathrm{c} 2, \mathrm{c} 4}$ & $18(19 \%)^{\mathrm{b} 3}$ & $12(13 \%)^{\mathrm{c5}, \mathrm{a} 4}$ & 94 \\
\hline Nonmucinous adenocarcinoma & $19(5.9 \%)^{\mathrm{c} 1, \mathrm{a} 1}$ & $126(39 \%)^{\mathrm{b} 2, \mathrm{c} 3, \mathrm{c} 4}$ & $101(31 \%)^{\mathrm{a} 3, \mathrm{~b} 3}$ & $75(23 \%)^{\mathrm{b} 5, \mathrm{~b} 6, \mathrm{a} 4}$ & 321 \\
\hline
\end{tabular}

Superscripts for statistical significance: ${ }^{\mathrm{a} 1-\mathrm{a} 4} P<0.05$; ${ }^{\mathrm{b} 1-\mathrm{b} 6} P<0.025$; ${ }^{\mathrm{c} 1-\mathrm{c} 5} P<0.01$; ${ }^{\mathrm{d}} P<0.005$.

ximately $4 \%$ of $B R A F$ mutations in carcinomas. $B R A F$ mutations were more frequent in the signet group (22-33\%) and in the mucinous group (15-27\%) than nonmucinous carcinoma $(8.6 \%)$ (Table 2). KRAS mutation distributions (ie, prevalence of each codon 12 or codon 13 mutation among all KRAS mutations) in the signet group, the mucinous group, and nonmucinous carcinoma did not significantly differ (data not shown). The KRAS mutation frequency in $\leq 49 \%$ mucinous tumors ( $47 \%$ ), but not that in $\geq 50 \%$ mucinous tumors (31\%), was significantly higher than nonmucinous carcinoma $(27 \%)$ (Table 2). TP53 positivity was less frequently observed in the mucinous group (31-41\%) than in nonmucinous carcinoma (56\%) (Table 2).

\section{Expression of MGMT, p16 (CDKN2A), COX2, and FASN}

MGMT and p16 immunohistochemistry is shown in Figure 1. MGMT loss was less frequent in the signet group $(0-26 \%)$ than in the $20-49 \%$ mucinous tumors $(53 \%)$ and in nonmucinous carcinoma $(34 \%)$, though statistical significance was not reached (Table 3). Interestingly, MGMT loss was more common in $20-49 \%$ mucinous tumors $(53 \%)$ than in $\geq 50 \%$ mucinous tumors $(18 \%)(P<0.025)$. Loss of p16 was less common in $\leq 49 \%$ mucinous tumors $(16 \%)$ than in nonmucinous tumors $(42 \%$; $P<0.001$ ) (Table 3).

COX2 and FASN immunohistochemistry is shown in Figures 2 and 3, respectively. There was no significant difference in distributions of COX2 staining intensities among the mucinous group and nonmucinous carcinoma $(\sim 5 \%$ showing $3+$ expression, $30-50 \% 2+$ expression, $20-30 \% 1+$ expression) (data not shown). COX2 expression was less common in tumors with any signet ring cell component $(50 \%)$ in nonmucinous carcinoma (76\%; $P<0.01$ ) (Table 3).
FASN expression was remarkable in that the mucinous group showed the highest levels of expression (58-77\% with $3+$ or $2+$ positivity), followed by nonmucinous carcinoma $(70 \%$ with $2+$ or $1+$ positivity), and the signet group most often showed low levels or no expression ( $\sim 75 \%$ showing $1+$ or negative staining) (Table 4 ).

\section{Discussion}

Signet ring cell colorectal carcinoma and mucinous colorectal adenocarcinoma are pathologically related, specific subtypes of colorectal adenocarcinoma. By convention, at least $50 \%$ of signet ring cell or mucinous component is required for the designation of signet ring cell carcinoma or mucinous carcinoma, respectively. We hypothesized that tumors with even less than $50 \%$ signet ring cell or mucinous component in colorectal adenocarcinoma imply molecular features similar to carcinoma with $50 \%$ or more signet ring cell or mucinous component, respectively. Our results support this hypothesis. There were some molecular differences, specifically frequencies of MSI and MGMT loss, between $\geq 50 \%$ mucinous carcinoma and $\leq 49 \%$ mucinous carcinoma. Statistically significant results by some of these pairwise comparisons might represent a result of multiple hypothesis testing, or a true biological difference. Nonetheless, in general, $\geq 50 \%$ mucinous carcinoma and $\leq 49 \%$ mucinous carcinoma appear similar, if not exactly the same. With regard to $\geq 50 \%$ signet ring cell carcinoma and $\leq 49 \%$ signet ring cell carcinoma, it seems that there is no significant difference. However, the number of tumors with a signet ring cell component, especially those with $\geq 50 \%$ signet ring cell component, is small and more cases are necessary to draw definitive conclusions. In light of our observations, we recommend that pathologists try to identify and report any minor component of signet ring cell 

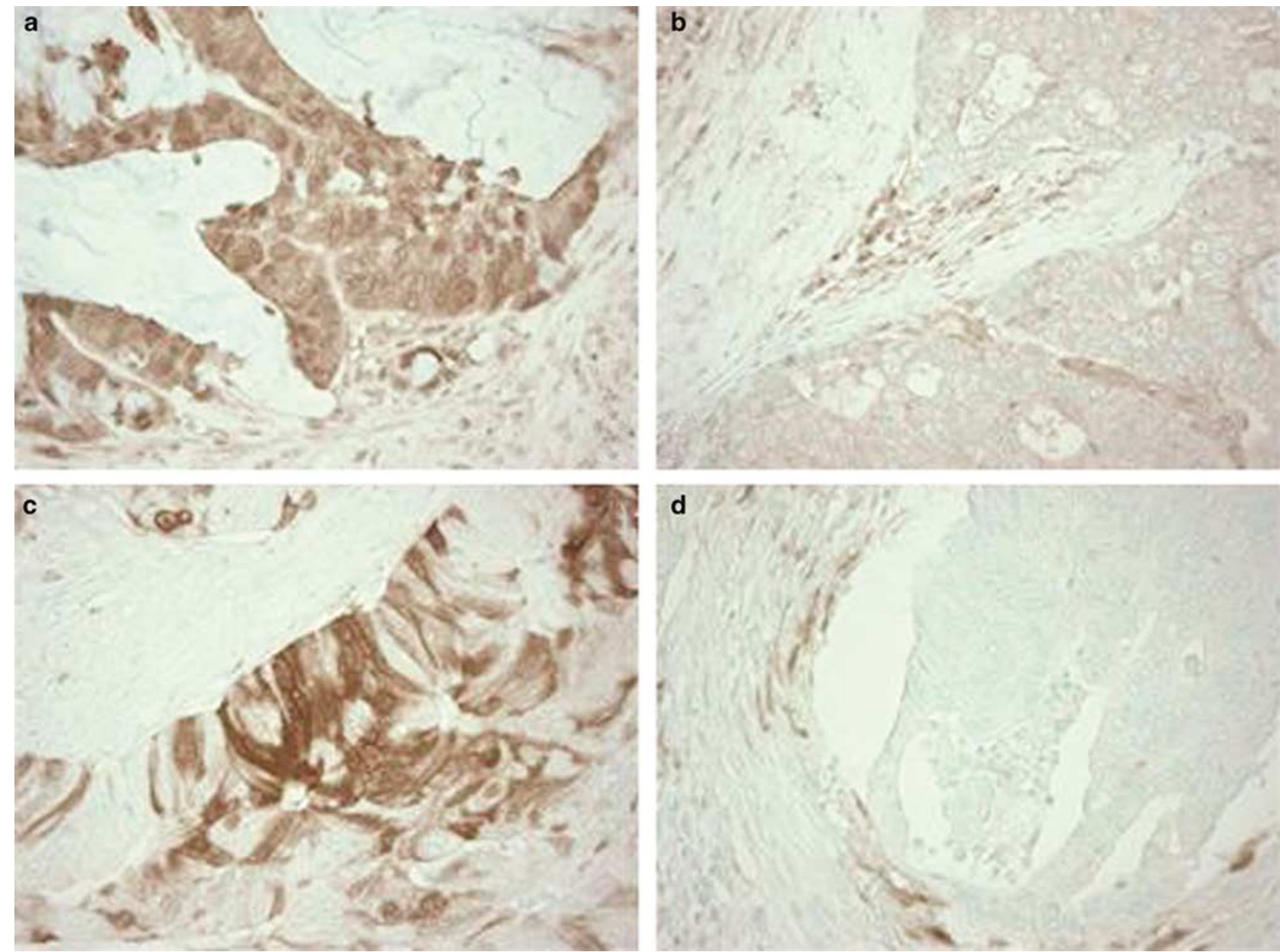

Figure 1 MGMT and p16 (CDKN2A) immunohistochemistry in colorectal carcinoma. (a) MGMT expression in mucinous carcinoma. (b) Loss of MGMT expression in nonmucinous carcinoma. Note that positive staining in mesenchymal and inflammatory cells serves as internal positive controls. (c) p16 expression in nonmucinous carcinoma. Note that p16 staining is focal. (d) Loss of p16 expression in nonmucinous carcinoma. Note that positive staining in mesenchymal cells serves as internal positive controls (original magnifications all $\times 400)$.

or mucinous areas in colorectal carcinoma, with efforts to quantify the amount of such a component. Since targeted therapy against specific deranged oncoproteins or signal transduction pathways may be available in the future, any findings that imply distinct molecular features should be reported.

We compared various molecular features between carcinoma with signet ring cell component (the signet group) and carcinoma with mucinous component, but no signet ring cell component (the mucinous group). There are molecular similarities among these groups, including higher frequencies of $B R A F$ mutation, MSI, and MLH1 loss. However, there are a number of molecular differences between the signet and mucinous groups. The mucinous group showed more frequent KRAS mutations, higher levels of COX2, and FASN expression than the signet group. Our results suggest that the signet and mucinous groups have overlapping, but distinct, pathogenetic mechanisms from each other.
Since chemotherapeutic agents that inhibit the activity of FASN have potential activity against many different cancers with FASN overexpression, ${ }^{24,28}$ our results of FASN expression (the highest expression in the mucinous group, followed by nonmucinous carcinoma, and the lowest expression in the signet group) may have some implications in treatment for colorectal cancer by FASN inhibitors in the future.

There are a number of differences between the signet group and nonmucinous non-signet ring cell carcinoma (simply referred to as 'nonmucinous carcinoma'). Compared to nonmucinous carcinoma, the signet group has more frequent $B R A F$ mutations, MSI and MLH1 loss, less frequent $18 \mathrm{q} \mathrm{LOH}$, and lower COX2 level. There are also a number of differences between the mucinous group and nonmucinous carcinoma. Compared to nonmucinous carcinoma, the mucinous group has more frequent $B R A F$ mutations, MSI, and MLH1 loss, less frequent TP53 mutation, and higher level of FASN expres- 

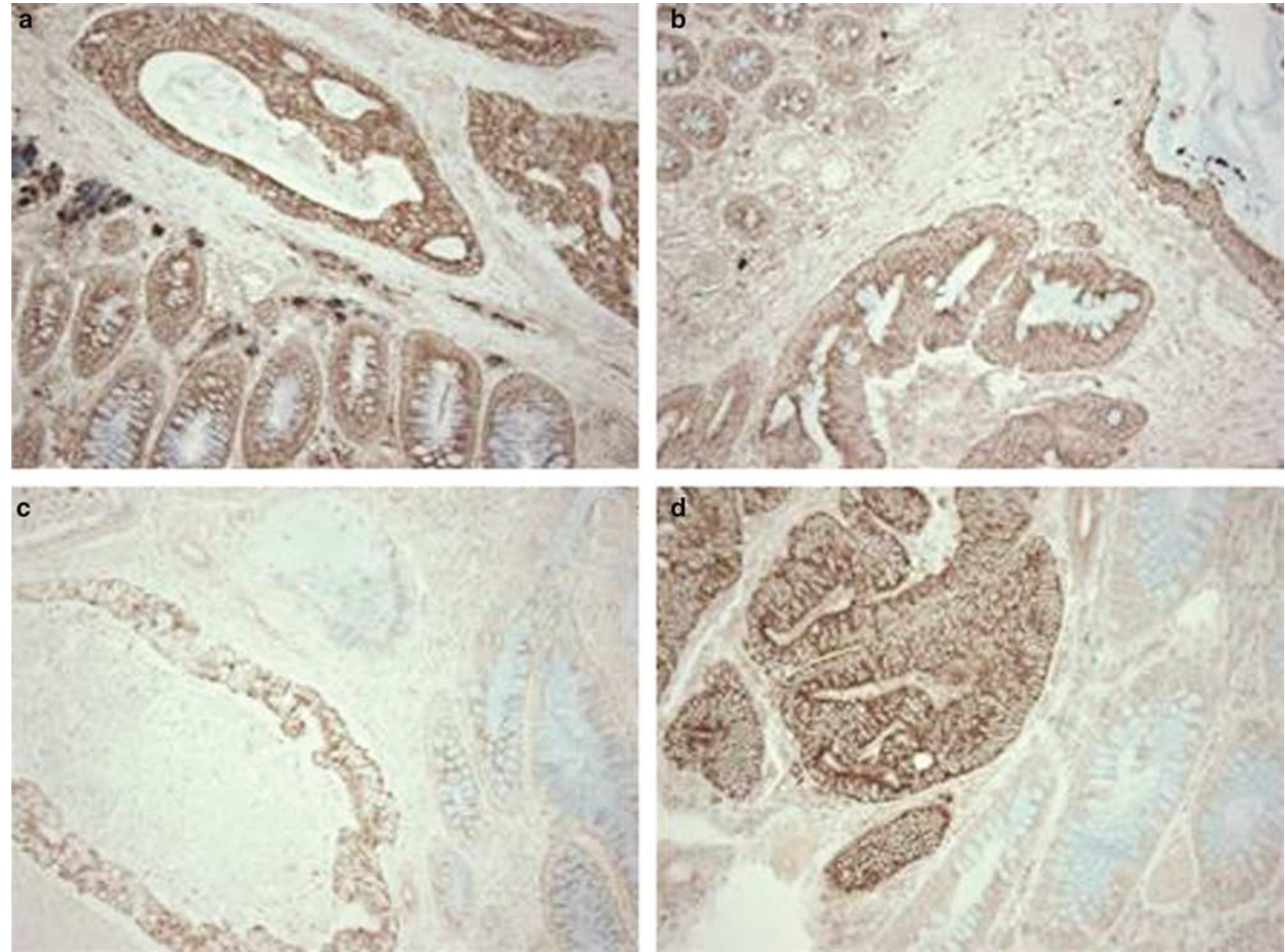

Figure 2 COX2 immunohistochemistry in colorectal carcinoma. (a) No or little COX2 overexpression in colorectal carcinoma (top) relative to normal mucosa (bottom). (b) Weak $(1+)$ COX2 overexpression in carcinoma with mucinous component (bottom and right) relative to normal mucosa (top left). (c) Moderate $(2+)$ COX2 overexpression in colorectal carcinoma (left) relative to normal mucosa (right). (d) Strong $(3+)$ COX2 overexpression in colorectal carcinoma (left) relative to normal mucosa (right) (original magnifications all $\times 200)$.

sion. Both signet ring cell carcinoma and mucinous colorectal carcinoma have been associated with MSI. $^{3-5}$ KRAS mutations were less common in signet ring cell carcinoma $(4 / 11=36 \%)$ and mucinous carcinoma $(11 / 29=38 \%)$ than in nonmucinous carcinoma $(18 / 30=60 \%)$ in a Japanese study. ${ }^{1}$ Other unique molecular abnormalities described in mucinous tumors include less frequent APC inactivation and KRAS mutation (28\%). ${ }^{4}$ Another study showed KRAS mutation frequency of $29 \%$ in mucinous tumors. ${ }^{41}$ Our results of KRAS mutation in $33 \%$ of mucinous tumors are also consistent with these findings.

Cyclooxygenase 2 (COX2) overexpression in colorectal carcinoma has been associated with poor prognosis. ${ }^{14}$ Expression of phospholipase A2, a key enzyme for prostaglandin synthesis together with COX2, has been associated with TNF-alpha-induced apoptosis in colon cancer cells. ${ }^{13}$ As lower COX2 levels have been reported in colorectal carcinoma with $\mathrm{MSI}^{42}$ we examined whether COX2 was expressed any differently among the signet group, the mucinous group, and nonmucinous carcinoma, depending on different MSI status. However, we did not observe any significant modifications of COX2 levels due to MSI status among these tumor groups (data not shown). Since COX2 is an attractive target of chemoprevention as well as targeted therapy for colorectal carcinoma, ${ }^{16,43}$ further investigations on various aspects of COX2 in colorectal carcinogenesis are awaited.

In conclusion, a minor signet ring cell or mucinous component in colorectal carcinoma implies molecular features similar to carcinoma with $\geq 50 \%$ signet ring cell component (signet ring cell carcinoma) or carcinoma with $\geq 50 \%$ mucinous component (mucinous carcinoma), respectively. Colorectal carcinoma with a signet ring cell component and carcinoma with a mucinous component are related subtypes of colorectal adenocarcinoma, but have distinct molecular features from each other. 

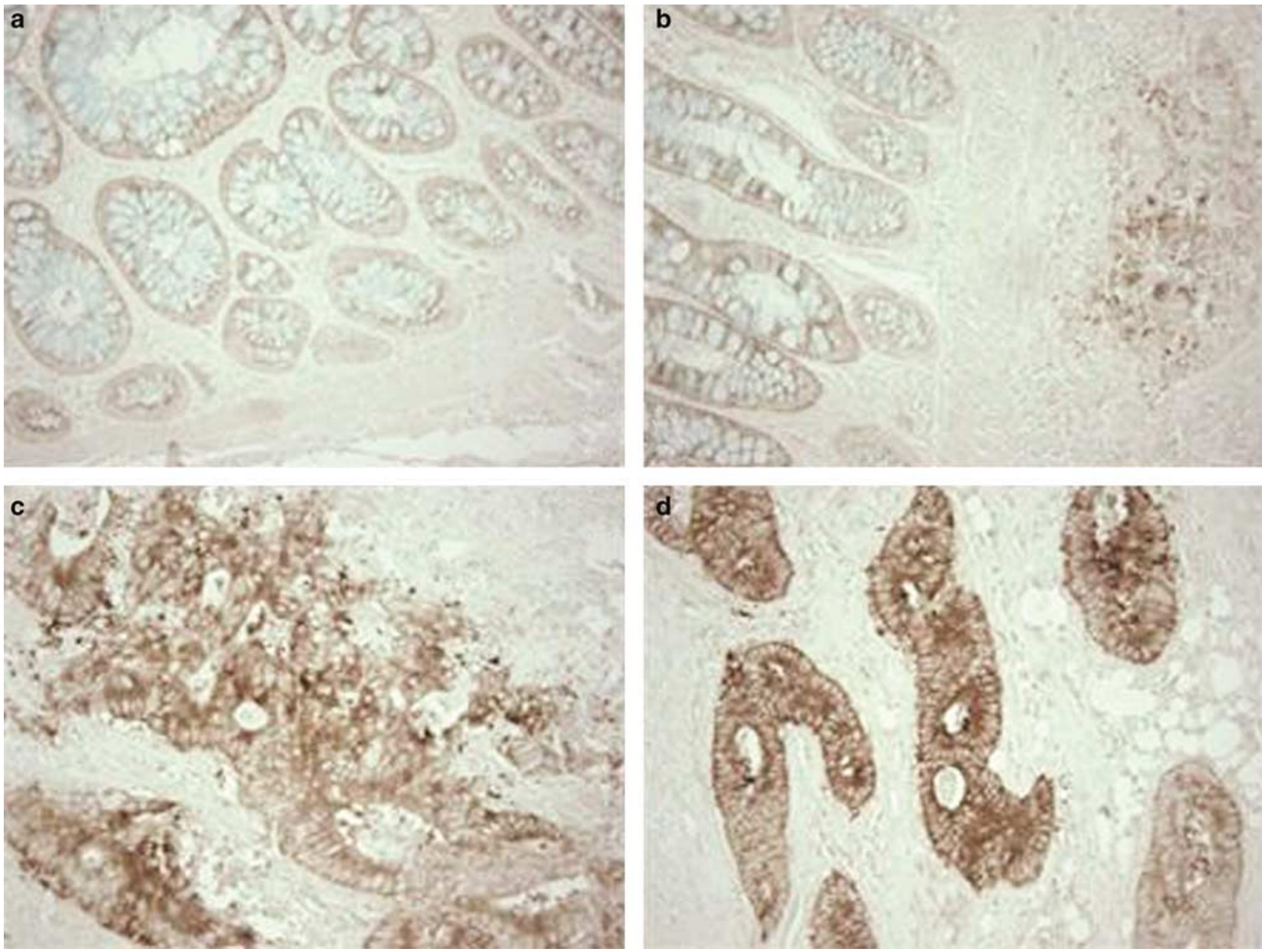

Figure 3 FASN immunohistochemistry in colorectal carcinoma. (a) Little FASN expression in normal colonic mucosa. (b) Weak (1+) FASN overexpression in colorectal carcinoma (right). Little FASN expression in normal mucosa (left). (c) Moderates (2+) FASN overexpression in colorectal carcinoma. (d) Strong $(3+)$ FASN overexpression in colorectal carcinoma (original magnifications all $\times 200)$.

\section{Acknowledgements}

This work was supported by NIH P01 CA87969-03 and P01 CA55075-13. We thank Graham Colditz, Walter Willett, Frank Speizer, Meir Stampfer, Edward Giovannucci, Eric Rimm, David Hunter, and all of the other staff members for establishment and follow-up of the two large epidemiologic cohorts, Nurses' Health Study and Health Professional Follow-up Study. We thank Mari Mino-Kenudson and Jonathan Glickman for critical reading of the manuscript and helpful suggestions.

\section{Notes added in proofs}

Detailed immunohistochemical methods for MLH1, CDKN2A (p16), MGMT and COX2 were as follows:

For MLH1 immunohistochemistry, antigen retrieval was performed by incubating deparaffinized tissue sections in $10 \mathrm{mM}$ citrate buffer (BioGenex, San Ramon, CA, USA) in a pressure cooker by a microwave for $30 \mathrm{~min}$. Tissue sections were incubated with $3 \% \mathrm{H}_{2} \mathrm{O}_{2}$ (20 min) to block endogenous peroxidase for $15 \mathrm{~min}$, and then incubated with $10 \%$ normal goat serum in phosphate-buffered saline (10 min). Tissue sections were further incubated with avidin block (Vector Laboratories, Burlingame, CA, USA) for $20 \mathrm{~min}$ and then with biotin block (Vector Laboratories) for 20 min. Primary antibody against MLH1 (BD Pharmingen, San Jose, CA, USA) (dilution 1:100) was applied for $30 \mathrm{~min}$ at room temperature. Multilink secondary antibody (BioGenex) (20 min), and then streptavidin horse radish peroxidase (BioGenex) were applied $(20 \mathrm{~min})$. Sections were visualized by diaminobenzidine (DAB) (5 min) and methyl-green counterstain. Normal colonic epithelial cells and inflammatory cells served as internal positive controls.

For CDKN2A (p16) immunohistochemistry, antigen retrieval was performed by incubating deparaffinized tissue sections in $10 \mathrm{mM}$ citrate buffer (BioGenex) by a microwave for $30 \mathrm{~min}$. Tissue 
sections were incubated with $3 \% \mathrm{H}_{2} \mathrm{O}_{2}(20 \mathrm{~min})$ to block endogenous peroxidase for $20 \mathrm{~min}$, and then incubated with $10 \%$ horse serum (Vector Laboratories) in phosphate-buffered saline $(20 \mathrm{~min})$. Primary antibody Ab-7 clone against CDKN2A (LabVision, Fremont, CA, USA) (dilution 1:200) was applied overnight at $4^{\circ} \mathrm{C}$. Secondary antibody (Vector Laboratories) (30 min) and then avidinbiotin complex conjugate (Vector Laboratories) were applied (30 min). Sections were visualized by DAB ( 5 min) and methyl-green counterstain. Some mesenchymal cells and inflammatory cells served as internal positive controls.

For MGMT immunohistochemistry, antigen retrieval was performed by incubating deparaffinized tissue sections in $10 \mathrm{mM}$ citrate buffer (BioGenex) by a microwave for $15 \mathrm{~min}$. Tissue sections were incubated with $3 \% \mathrm{H}_{2} \mathrm{O}_{2}(20 \mathrm{~min})$ to block endogenous peroxidase for $20 \mathrm{~min}$, and then incubated with $10 \%$ horse serum (Vector Laboratories) in phosphate-buffered saline $(20 \mathrm{~min})$. Tissue sections were further incubated with avidin block (BioGenex) for $15 \mathrm{~min}$ and then with biotin block (BioGenex) for 15 min. Primary antibody against MGMT (Chemicon, Temecula, CA, USA) (dilution 1:50) was applied overnight at $4^{\circ} \mathrm{C}$. Secondary antibody (Vector Laboratories) (30 min) and then avidinbiotin complex conjugate (Vector Laboratories) were applied (30 min). Sections were visualized by DAB (5 min) and methyl-green counterstain. Normal colonic epithelial cells and inflammatory cells served as internal positive controls.

For COX2 immunohistochemistry, antigen retrieval was performed by incubating deparaffinized tissue sections in citrate buffer (BioGenex) by a microwave for $15 \mathrm{~min}$, and letting the sections cool for at least $40 \mathrm{~min}$. Tissue sections were incubated with $3 \% \mathrm{H}_{2} \mathrm{O}_{2}(20 \mathrm{~min})$ to block endogenous peroxidase, and then incubated with Avidin Block (Vector Laboratories) (15 min), then with Biotin Block (Vector Laboratories) (15 min). Primary anti-COX2 antibody (Cayman Chemical, Ann Arbor, MI, USA) (dilution 1:300) was applied overnight at $4^{\circ} \mathrm{C}$. Then, secondary anti-mouse antibody (Vector Laboratories) was applied (20 min), avidin-biotin complex conjugate (Vector Laboratories) was added and sections were visualized by $\mathrm{DAB}$ ( $5 \mathrm{~min}$ ) and methyl-green counterstain. COX2 expression was interpreted as negative, weak $(1+)$, positive $(2+)$ and strongly positive $(3+)$, using normal epithelial and inflammatory cells as reference.

\section{References}

1 Sasaki S, Masaki T, Umetani N, et al. Characteristics in primary signet-ring cell carcinoma of the colorectum, from clinicopathological observations. Jpn J Clin Oncol 1998;28:202-206.

2 Tung SY, Wu CS, Chen PC. Primary signet ring cell carcinoma of colorectum: an age- and sex-matched controlled study. Am J Gastroenterol 1996;91:21952199.

3 Kawabata Y, Tomita N, Monden T, et al. Molecular characteristics of poorly differentiated adenocarcinoma and signet-ring-cell carcinoma of colorectum. Int J Cancer 1999;84:33-38.

4 Song GA, Deng G, Bell I, et al. Mucinous carcinomas of the colorectum have distinct molecular genetic characteristics. Int J Oncol 2005;26:745-750.

5 Kakar S, Smyrk TC. Signet ring cell carcinoma of the colorectum: correlations between microsatellite instability, clinicopathologic features and survival. Mod Pathol 2005;18:244-249.

6 Wistuba II, Behrens C, Albores-Saavedra J, et al. Distinct K-ras mutation pattern characterizes signet ring cell colorectal carcinoma. Clin Cancer Res 2003;9: 3615-3619.

7 Alexander J, Watanabe T, Wu TT, et al. Histopathological identification of colon cancer with microsatellite instability. Am J Pathol 2001;158:527-535.

8 Peyssonnaux C, Eychene A. The Raf/MEK/ERK pathway: new concepts of activation. Biol Cell 2001;93: 53-62.

9 Davies H, Bignell GR, Cox C, et al. Mutations of the BRAF gene in human cancer. Nature 2002;417: 949-954.

10 Rajagopalan H, Bardelli A, Lengauer C, et al. Tumorigenesis: RAF/RAS oncogenes and mismatch-repair status. Nature 2002;418:934.

11 Wang L, Cunningham JM, Winters JL, et al. BRAF mutations in colon cancer are not likely attributable to defective DNA mismatch repair. Cancer Res 2003;63: 5209-5212.

12 Koinuma K, Shitoh K, Miyakura Y, et al. Mutations of BRAF are associated with extensive hMLH1 promoter methylation in sporadic colorectal carcinomas. Int J Cancer 2004;108:237-242.

13 Dong M, Johnson M, Rezaie A, et al. Cytoplasmic phospholipase A2 levels correlate with apoptosis in human colon tumorigenesis. Clin Cancer Res 2005;11: 2265-2271.

14 Soumaoro LT, Uetake H, Higuchi T, et al. Cyclooxygenase-2 expression: a significant prognostic indicator for patients with colorectal cancer. Clin Cancer Res 2004;10:8465-8471.

15 Smakman N, Kranenburg O, Vogten JM, et al. Cyclooxygenase-2 is a target of KRASD12, which facilitates the outgrowth of murine C26 colorectal liver metastases. Clin Cancer Res 2005;11:41-48.

16 Kazanov D, Dvory-Sobol H, Pick M, et al. Celecoxib but not rofecoxib inhibits the growth of transformed cells in vitro. Clin Cancer Res 2004;10:267-271.

17 Semenkovich CF. Regulation of fatty acid synthase (FAS). Prog Lipid Res 1997;36:43-53.

18 Rossi S, Graner E, Febbo P, et al. Fatty acid synthase expression defines distinct molecular signatures in prostate cancer. Mol Cancer Res 2003;1:707-715.

19 Swinnen JV, Heemers H, Deboel L, et al. Stimulation of tumor-associated fatty acid synthase expression by growth factor activation of the sterol regulatory element-binding protein pathway. Oncogene 2000;19: 5173-5181.

20 Alo PL, Visca P, Marci A, et al. Expression of fatty acid synthase (FAS) as a predictor of recurrence in stage I breast carcinoma patients. Cancer 1996;77:474-482.

21 Gansler TS, Hardman III W, Hunt DA, et al. Increased expression of fatty acid synthase (OA-519) in ovarian 
neoplasms predicts shorter survival. Hum Pathol 1997; 28:686-692.

22 Shurbaji MS, Kalbfleisch JH, Thurmond TS. Immunohistochemical detection of a fatty acid synthase (OA519) as a predictor of progression of prostate cancer. Hum Pathol 1996;27:917-921.

23 Rashid A, Pizer ES, Moga M, et al. Elevated expression of fatty acid synthase and fatty acid synthetic activity in colorectal neoplasia. Am J Pathol 1997;150:201-208.

24 Kuhajda FP. Fatty-acid synthase and human cancer: new perspectives on its role in tumor biology. Nutrition 2000;16:202-208.

25 Visca P, Alo PL, Del Nonno F, et al. Immunohistochemical expression of fatty acid synthase, apoptoticregulating genes, proliferating factors, and ras protein product in colorectal adenomas, carcinomas, and adjacent nonneoplastic mucosa. Clin Cancer Res 1999; 5:4111-4118.

26 Takahiro T, Shinichi K, Toshimitsu S. Expression of fatty acid synthase as a prognostic indicator in soft tissue sarcomas. Clin Cancer Res 2003;9:2204-2212.

27 Menendez JA, Vellon L, Colomer R, et al. Pharmacological and small interference RNA-mediated inhibition of breast cancer-associated fatty acid synthase (oncogenic antigen-519) synergistically enhances Taxol (paclitaxel)-induced cytotoxicity. Int J Cancer 2005;115:19-35.

28 Kuhajda FP, Pizer ES, Li JN, et al. Synthesis and antitumor activity of an inhibitor of fatty acid synthase. Proc Natl Acad Sci USA 2000;97:3450-3454.

$29 \mathrm{Li}$ JN, Gorospe M, Chrest FJ, et al. Pharmacological inhibition of fatty acid synthase activity produces both cytostatic and cytotoxic effects modulated by p53. Cancer Res 2001;61:1493-1499.

30 Kridel SJ, Axelrod F, Rozenkrantz N, et al. Orlistat is a novel inhibitor of fatty acid synthase with antitumor activity. Cancer Res 2004;64:2070-2075.

31 Fuchs CS, Willett WC, Colditz GA, et al. The influence of folate and multivitamin use on the familial risk of colon cancer in women. Cancer Epidemiol Biomarkers Prev 2002;11:227-234.

32 Colditz GA, Hankinson SE. The Nurses' Health Study: lifestyle and health among women. Nat Rev Cancer 2005;5:388-396.

33 Dietmaier W, Hartmann A, Wallinger S, et al. Multiple mutation analyses in single tumor cells with improved whole genome amplification. Am J Pathol 1999;154: 83-95.

34 Ogino S, Kawasaki T, Brahmandam M, et al. Sensitive sequencing method for KRAS mutation detection by pyrosequencing. J Mol Diagn 2005;7:413-421.

35 Ogino S, Meyerhardt J, Cantor M, et al. Molecular alterations in tumors and response to combination chemotherapy with gefitinib (ZD1839, EGFR tyrosine kinase inhibitor) for advanced colorectal cancer. Clin Cancer Res 2005 (in press).

36 Boland CR, Thibodeau SN, Hamilton SR, et al. A National Cancer Institute Workshop on microsatellite instability for cancer detection and familial predisposition: development of international criteria for the determination of microsatellite instability in colorectal cancer. Cancer Res 1998;58:5248-5257.

37 Reles A, Schmider A, Press MF, et al. Immunostaining of p53 protein in ovarian carcinoma: correlation with histopathological data and clinical outcome. J Cancer Res Clin Oncol 1996;122:489-494.

38 Riethdorf L, Riethdorf S, Lee KR, et al. Human papillomaviruses, expression of p16, and early endocervical glandular neoplasia. Hum Pathol 2002;33: 899-904.

39 Esteller M, Hamilton SR, Burger PC, et al. Inactivation of the DNA repair gene O6-methylguanine-DNA methyltransferase by promoter hypermethylation is a common event in primary human neoplasia. Cancer Res 1999;59:793-797.

40 Kane MF, Loda M, Gaida GM, et al. Methylation of the hMLH1 promoter correlates with lack of expression of hMLH1 in sporadic colon tumors and mismatch repairdefective human tumor cell lines. Cancer Res 1997;57: 808-811.

41 Ikeda S, Shimizu Y, Fujimori M, et al. Immunohistochemical and mutational analyses of beta-catenin, Ki-ras, and p53 in two subtypes of colorectal mucinous carcinoma. Clin Cancer Res 2003;9:5660-5665.

42 Karnes Jr WE, Shattuck-Brandt R, Burgart LJ, et al. Reduced COX-2 protein in colorectal cancer with defective mismatch repair. Cancer Res 1998;58:54735477.

43 Dannenberg AJ, Lippman SM, Mann JR, et al. Cyclooxygenase-2 and epidermal growth factor receptor: pharmacologic targets for chemoprevention. J Clin Oncol 2005;23:254-266. 